More Information

\section{Protection from the Pathogenesis} of Neurodegenerative Disorders, including Alzheimer's Disease, Amyotrophic Lateral Sclerosis, Huntington's Disease, and Parkinson's Diseases, through the Mitigation of Reactive Oxygen Species

\author{
Samskruthi Madireddy* and Sahithi Madireddy \\ 1353 Tanaka Drive, San Jose, CA 95131, USA
}

\section{Abstract}

The biological changes caused by oxidative stress (OS) are known to be involved in the etiology of neurodegenerative disorders, including Alzheimer's disease, amyotrophic lateral sclerosis, Huntington's disease, and Parkinson's disease. The brain is particularly vulnerable to OS due to its high lipid content and extensive consumption of oxygen. OS processes, particularly the excessive production of reactive oxygen species (ROS), play a critical role in how neurodegenerative disorders develop. This is evidenced by in vivo studies investigating various biomolecules related to OS, such as products of lipid and DNA oxidation. Accordingly, ROS can also cause oxidativerelated damage in neurodegenerative disorders, including dopamine auto-oxidation, mitochondrial dysfunction, glial cell activation, a-synuclein aggregation, excessive free iron, and changes in calcium signaling. Furthermore, excessive levels of cellular oxidants reduce antioxidant defenses, which in turn propagate the cycle of OS. As such, it is increasingly important to determine the linkage between a high intake of antioxidants through dietary interventions and a lower risk of developing neurodegenerative diseases. Indeed, in addition to modulating the immune system, optimal nutritional status is capable of changing various processes of neuroinflammation known to be involved in the pathogenesis of neurodegeneration. Accordingly, a better understanding of the role ROS plays in the etiology of neurodegeneration is needed, along with the identification of dietary interventions that may lead to improved therapeutic strategies for both the treatment and prevention of neurodegenerative disorders. Therefore, this review presents a comprehensive summary of the role of ROS in the pathogenesis of neurodegenerative disorders. In addition, nutrients believed to be useful for mitigating and counteracting ROS are discussed.
*Address for Correspondence: Samskruthi Madireddy, 1353 Tanaka Drive, San Jose, CA 95131, USA, Tel: +408-832-4848; Email: samskruthi.madireddy@gmail.com

Submitted: 23 October 2019

Approved: 01 November 2019

Published: 04 November 2019

How to cite this article: Madireddy S, Madireddy S. Protection from the Pathogenesis of Neurodegenerative Disorders, including Alzheimer's Disease, Amyotrophic Lateral Sclerosis, Huntington's Disease, and Parkinson's Diseases, through the Mitigation of Reactive Oxygen Species. J Neurosci Neurol Disord. 2019; 3. $148-161$

DOI: dx.doi.org/10.29328/journal.jnnd.1001026

Copyright: (C) 2019 Madireddy S, et al. This is an open access article distributed under the Creative Commons Attribution License which permits unrestricted use, distribution, and reproduction in any medium, provided the original work is properly cited

Keywords: Alzheimer's disease; Amyotrophic lateral sclerosis; Huntington's disease; Parkinson's disease; Nutrients; Oxidative stress; Reactive oxygen species

Check for updates

\section{Introduction}

In order for the central nervous system (CNS) to function normally, the brain should be free from biochemical impairments [1,2]. Oxidative stress (OS) is one of the main factors that contribute to the biochemical impairment of the brain [3]. Due to its high oxygen consumption and lipid content, the brain is highly susceptible to OS [4,5]. OS stems from an imbalance in the cellular antioxidant response system, which can occur as a result of low dietary antioxidant consumption [6,7]. In particular, OS denotes an imbalance between the creation of reactive oxygen species (ROS) and the mitigating effects of antioxidants [5]. In turn, excessive cellular oxidant levels are known to reduce antioxidant levels [8]. Accordingly, high oxygen consumption is known to cause extensive ROS production, with the resulting accumulation of ROS contributing to a decline in cellular antioxidants [5,9]. In this review, we emphasize the role of ROS in the pathogenesis of various neurodegenerative diseases, including Alzheimer's disease (AD), amyotrophic lateral sclerosis (ALS), Huntington's disease (HD), and Parkinson's disease (PD). 
Antioxidant-based treatments are quickly emerging as an encouraging option to delay the progression of neurological diseases $[10,11]$. Indeed, the consumption of antioxidant-rich foods has been shown to help reduce the extent of oxidative damage caused by free radicals, which are produced during various pathological processes, including amyloid-beta $(A \beta)$ accumulation, altered antioxidant defenses, inflammation, and mitochondrial anomalies [12,13]. Accordingly, antioxidant treatments can facilitate neuroprotection by delaying the occurrence or even reversing OS in some cases [14]. In addition, diet is known to play a key role in neurodegenerative diseases, and the development of irreversible neurocognitive decline can be prevented or delayed by the consumption of certain nutrients and appropriate dietary modifications $[15,16]$. Therefore, nutrients known to be useful in mitigating or counteracting ROS in neurodegenerative disorders will also be discussed.

\section{Oxidative stress and reactive oxygen species}

Although oxygen is crucial to life and is involved in numerous biological processes, including gene transcription and signal transduction, it can also have negative impacts on biomolecules via ROS and free radicals [7,17]. The adverse effects of oxygen can be attributed to its univalent metabolic reduction status, which leads to the development of ROS [9]. The accumulation of ROS results in a cellular state of OS, which is defined as an imbalance between a biological system's oxidant and antioxidant levels [18]. This imbalance can be caused by excessive levels of ROS or dysfunction in the cellular antioxidant system [19,20].

Free radicals refer to molecular fragments that contain at least one unpaired electron in their respective molecular/ atomic orbitals [21]. These unpaired electron(s) provide free radicals with copious amounts of reactivity, with oxygen free radicals representing the most significant category of radical species in living organisms [22]. In general, the production of oxygen free radicals occurs during reactions associated with cellular metabolism [18]. Indeed, during the transduction of energy, a limited number of electrons end up leaking prematurely to oxygen for the generation of superoxide $\left(\mathrm{O}_{2}{ }^{--}\right)$ [23]. In addition, during periods of OS, excessive amounts of $\mathrm{O}_{2} \cdot{ }^{--}$serve to expel iron from iron-containing molecules, leading to the generation of the extremely reactive hydroxyl radical $\left({ }^{\circ} \mathrm{OH}\right)$ through the Fenton reaction [22]. As a result, the formation of additional reactive radicals can occur, including the generation of peroxyl radicals [17]. The perhydroxyl radical, otherwise known as the hydroperoxyl radical, is considered the simplest of such radical. Hydroperoxyl radicals can initiate the peroxidation of fatty acids [17]. In addition, $\mathrm{O}_{2}{ }^{\cdot-}$ can swiftly react with NO to generate peroxynitrite, which is a reactive nitrogen species (RNS) that can inflict significant damage to intracellular components [18,24]. In this manner, the term ROS is inclusive of ${ }^{\circ} \mathrm{OH}, \mathrm{O}_{2}{ }^{--}$, and hydrogen peroxide $\left(\mathrm{H}_{2} \mathrm{O}_{2}\right)[21,25]$.

\section{Oxidative damage}

ROS can cause serious harm to macromolecules, including nucleic acids, lipids, proteins, and polysaccharides $[4,6,26]$. In terms of the CNS, certain properties of neurons make them particularly susceptible to the deleterious effects of ROS. These properties include a composition of fatty acids that is vulnerable to peroxidation, high rates of metabolism, heightened concentrations of transition metals, low antioxidant levels, and a lower regenerative capacity [22].

In addition, neurons experience intense demands related to energy, with the mitochondria both an important source and target of ROS [27]. OS is also known to stimulate mitochondrial fission [28]. This is evidenced by studies wherein $\mathrm{H}_{2} \mathrm{O}_{2}$ is added onto cultured cerebellar granule neurons, which induces mitochondrial fragmentation within an hour of treatment [29].

OS can also lead to alterations in the structure of proteins, and impaired protein structures can further exacerbate oxidative damage [9]. Indeed, ROS causes protein oxidization and modified protein structures that easily aggregate and dimerize [30]. These functionally and structurally abnormal oxidized proteins then accumulate within the cytoplasm of neurons in the form of $A ß$ plaques and tau neural fibrillary tangles (NFT) [31]. Aß plaques themselves are also known to be responsible for the formation of ROS, resulting in a continuous cycle of OS [30]. In addition, a growing body of evidence has demonstrated that ROS causes oxidative damage to lipids and DNA, which leads to various cellular dysfunctions $[4,32,33]$. In summary, oxidative damage is inclusive of dopamine autooxidation, mitochondrial dysfunction, glial cell activation, $\alpha$-synuclein aggregation, changes in calcium signaling, and excessive free iron [34-36].

\section{Oxidative stress and neurodegenerative disorders}

Sustained oxidative stress, in particular, ROS may also trigger abnormalities in mitochondrial function, impairment of the DNA repair system, and cellular damage, all of which are considered to play decisive roles in accelerating the aging process and the development of neurodegenerative disorders $[37,38]$. Indeed, a large body of evidence exists underscoring the role of ROS in several human disease states, including neurodegenerative disorders [39-42]. Therefore, continued efforts are critical to identifying agents that could be potentially useful in the treatment and prevention of neurodegenerative diseases $[7,43]$. Many studies have observed the association between the accumulation of ROS and the pathogenesis of neurodegenerative disorders, including Alzheimer's disease, amyotrophic lateral sclerosis, Huntington's disease, and Parkinson's diseases [39-41,44]. In brief, Alzheimer's disease is a neurodegenerative disorder that is characterized by the progressive loss of memory and the development of dementia $[45,46]$, whereas Huntington's disease refers to a hereditary disorder of the CNS $[40,42]$. The symptoms of Huntington's disease include cognitive impairments, movement disorders, 
and psychiatric disorders [47]. Amyotrophic lateral sclerosis is a serious neuromuscular disorder characterized by the loss of motor neurons and significant skeletal muscle wasting over a short period of time [48].

In contrast, Parkinson's disease is considered a longterm, progressive age-related neurodegenerative disease characterized by motor dysfunction $[49,50]$.

\section{Alzheimer's Disease (AD)}

Alzheimer disease is a brain-specific disorder characterized by the presence of tau NFT, neural inflammation, and $A \beta$ plaques [51-53]. These pathologies cause neuronal death and concomitant clinical symptoms, such as confusion, impaired cognitive function, and memory loss [54-56]. One of the key characteristics of $\mathrm{AD}$ is the substantial and progressive erosion of neurons in the cortex [57]. Indeed, maximal degeneration takes place in the cortex and hippocampus, which leads to deficiencies in both learning and memory [58]. Typically, $\mathrm{AD}$ symptoms commence with mild amnesia and confusion, eventually leading to radical changes in the personality of the afflicted individual [59]. Other AD signs include vision/spatial abnormalities, poor word recall, and deficits in judgment or reasoning [59].

\section{Alzheimer's disease and oxidative stress}

An imbalance between ROS production and the activities of enzymes responsible for ROS scavenging results in increased oxidative damage in AD patients [54]. Numerous studies have demonstrated that OS and ROS have a significant role in AD by causing deleterious effects to proteins and other important biomolecules $[20,60]$. ROS oxidize $\beta$-amyloid and tau, and the resulting oxidative imbalanceleads to further neuronal damage in $\mathrm{AD}$ patients $[61,62]$. These oxidized proteins accumulate in the cytoplasm of neurons to create $A \beta$ plaques, which serve to propagate the cycle of oxidative damage via increasing ROS levels $[63,64]$. Another contribution of OS to AD is through mitochondrial dysfunction caused by the accumulation of the $A \beta$ aggregates [54]. In this regard, mitochondrial dysfunction is a key protagonist in the pathogenesis of $\mathrm{AD}$ $[12,65,66]$. In particular, mitochondrial dysfunction is caused by a number of factors, including oxidative stress from the generation of ROS, membrane damage, mitochondrial damage (DNA-related), the destabilization of ionic gradients, and interactions with $A \beta$, which is regarded as a toxic protein $[67,68]$. According to emerging evidence, there may be an association between tau pathology and OS $[69,70]$. Indeed, cells containing overexpressed tau proteins appear to be particularly vulnerable to OS [71]. In summary, amyloid plaque, Tau aggregation, excessive generation of ROS, mitochondrial dysfunction, accumulation of Iron and impaired calcium homeostasis, and poor antioxidant status generates oxidative stress, particularly ROS in AD. Enhanced oxidative alterations to $\beta$-amyloid protein lead to protein misfolding and protein aggregation which in turn causes exacerbation of neurodegeneration and death of neuronal cells in AD [22]. The destruction of the cells leads to brain atrophy in AD.

\section{Alzheimer's disease and nutrients}

Bioactive nutrients are believed to be some of the few factors that are effective in AD (Table 1) [72]. A growing body of evidence indicates that a wholesome dietary plan consisting of fish, fruit, and vegetables is important for optimizing cognition and reducing the risk of $\mathrm{AD}$ [73]. In particular, reduced levels of fat-soluble vitamins, such as vitamins A, D, E, and K, may be responsible for causing a cognitive decline among $\mathrm{AD}$

Table 1: Summary of nutraceuticals suggested for prevention and therapy of neurodegenerative diseases.

\begin{tabular}{|c|c|c|c|}
\hline Nutraceuticals & Beneficial Effects & Mechanism & Support for Diseases \\
\hline Vitamin $\mathrm{E}$ & $\begin{array}{l}\text { Antioxidant, } \\
\text { Neuroprotection }\end{array}$ & $\begin{array}{l}\text { Vitamin } \mathrm{E} \text { is a scavenger of several ROS and serves to reduce their reactivity and toxicity. It offers } \\
\text { protection from the propagative damage of ROS by inhibiting the oxidative modification of lipoproteins }\end{array}$ & $\begin{array}{c}\text { AD }[74-79,82-86] \\
\text { PD }[175-177,79] \\
\text { ALS }[193,217,218]\end{array}$ \\
\hline Vitamin C & $\begin{array}{l}\text { Antioxidant, } \\
\text { Neuroprotection }\end{array}$ & $\begin{array}{l}\text { Vitamin C is an excellent antioxidant, suitable in reducing ROS levels, lipid peroxidation, and oxidative } \\
\text { stress. It is also useful in regenerating other antioxidants. }\end{array}$ & $\begin{array}{c}\text { AD }[81,82,75,77,79] \\
\text { PD }[166-168] \\
\text { ALS }[213,214]\end{array}$ \\
\hline Vitamin D & Antioxidant Neuroprotection & $\begin{array}{l}\text { Vitamin D prevent oxidative stress, lower the production of free radicals, and reduce neurotoxicity } \\
\text { through the enhancement of autophagy signaling pathways }\end{array}$ & $\begin{array}{c}\text { AD }[74-78,30,16,80] \\
\text { PD }[157-159,169-174] \\
\text { ALS }[215,216]\end{array}$ \\
\hline Vitamin A & Antioxidan & Vitamin $A$ prevent the formation of $A \beta$ plaques & $\mathrm{AD}[16,30,74-78]$ \\
\hline Vitamin B & $\begin{array}{l}\text { Antioxidant } \\
\text { Neuroprotection }\end{array}$ & Vitamin B perform antioxidant and neuroprotective functions & $\begin{array}{c}\text { AD [88-90] } \\
\text { PD [157-159,162-165] } \\
\text { HD }[105]\end{array}$ \\
\hline Curcumin & $\begin{array}{c}\text { Antioxidant } \\
\text { Anti-inflammatory } \\
\text { Neuroprotection }\end{array}$ & Curcumin is a scavenger of free radicals and reduces mitochondrial disfunction. & $A D[100,101]$ \\
\hline $\begin{array}{l}\text { Omega-3 } \\
\text { fatty acids }\end{array}$ & $\begin{array}{l}\text { Antioxidant } \\
\text { Anti-inflammatory }\end{array}$ & Omega-3 fatty acids reduce ROS formation acting as free radical scavengers. & $\begin{array}{c}\text { AD }[92-94] \\
\text { PD }[175,180-182] \\
\text { ALS }[193,217]\end{array}$ \\
\hline Flavonoids & $\begin{array}{c}\text { Antioxidant } \\
\text { Anti-inflammatory } \\
\text { Neuroprotection } \\
\text { Neuromodulation }\end{array}$ & Flavonoids scavenge ROS and acts as antioxidative, antiapoptotic, and anti-inflammatory agent. & $\begin{array}{l}\text { AD }[95-97] \\
\text { PD }[97,185-188]\end{array}$ \\
\hline Polyphenols & $\begin{array}{c}\text { Antioxidant, } \\
\text { Anti-inflammatory, } \\
\text { Anti-apoptotic }\end{array}$ & $\begin{array}{l}\text { Polyphenols reduces the levels of } A \beta \text { and offers antioxidant, anti-inflammatory, mitochondrial } \\
\text { protective, and anti-apoptotic activities. }\end{array}$ & $\begin{array}{c}A D[95-97] \\
\operatorname{HD}[42,43,95,125] \\
\operatorname{PD}[95,183,184]\end{array}$ \\
\hline
\end{tabular}


patients [30,74-76]. Antioxidants that may help treat AD as adjuvants to traditional therapies include vitamins $\mathrm{A}, \mathrm{C}$, and $\mathrm{E}[16,30,75,77]$. Vitamin $\mathrm{A}$ has been reported to prevent the formation of $A \beta$ plaques [78]. In addition, vitamins $C$ and $E$ have also proven to be beneficial in delaying or preventing the progression to irreversible neurocognitive decline [79]. Furthermore, higher consumption of vitamin D is associated with a lower risk of $\mathrm{AD}$ [80].

Studies have suggested that vitamin $\mathrm{C}$ may be able to halt the development of $\mathrm{AD}$ due to its role in mitigating various processes associated with AD pathology [81]. Both in vitro and in vivo studies have reported that vitamin $C$ helps reduce OS by impeding $A ß$ oligomerization $[11,15]$. Damage to the brain leads to a decline in antioxidants and important enzymes, including vitamin $\mathrm{C}$ and superoxide dismutase (SOD), which neutralizes $\mathrm{O}_{2}{ }^{--}$radicals [81]. Vitamin C itself can help increase SOD levels and decrease levels of associated OS [81]. Indeed, researchers have postulated that even a normal vitamin $\mathrm{C}$ intake through diet can exert a neuroprotective effect among AD patients [30]. A study of 4,740 participants showed that an intake of vitamins $E$ and $C$ for at least three years reduced the risk of developing $\mathrm{AD}$ [82]. Vitamin $\mathrm{E}$ is considered to be an important antioxidant micronutrient, and studies have shown that vitamin E can safeguard cells from oxidative damage $[75,83]$. In addition, vitamin $E$ offers protection from the propagative damage of ROS by inhibiting the oxidative modification of lipoproteins [84,85]. Indeed, a study comprising 904 patients with $\mathrm{AD}$ and 1,153 healthy older controls confirmed that serum vitamin E levels were lower in the AD patients compared with the controls [86]. In this regard, an increased intake of quality dairy, fresh fruit, vegetables, fish, and whole grains, along with the reduced consumption of fried potatoes, sweets, and processed meat, may provide an efficacious nutrient combination and offer protection against $\mathrm{AD}[84,87]$.

In addition, various $\mathrm{B}$ vitamins, including folate (or $\mathrm{B}_{9}$ ), $B_{6}$, and $B_{12}$, have been reported to have a positive impact on $\mathrm{AD}$ patients in terms of their influence on the metabolism of homocysteine, which is a sulfur amino acid source derived from the metabolism of methionine [88-90]. In addition, magnesium, inositol, choline, $\mathrm{B}_{1}$, isoflavones, and anthocyanins may help prevent the development of $\mathrm{AD}$ [91]. In addition, dietary omega- 3 fatty acids are also known to improve the functioning of the brain in a similar manner [92,93]. A study comprising 815 participants between the ages of 65 and 94 found a $60 \%$ lower risk of developing $\mathrm{AD}$ in those who consumed fish at least once per week [94].

A growing body of evidence suggests that polyphenols and flavonoids scavenge RNS and ROS, thus playing an important beneficial role in patients suffering from degenerative diseases related to aging [95-97]. Polyphenols are key antioxidant substances found in abundant quantities in various fruits, such as grapes, blueberries, and tomatoes, vegetables, olive oil, spices, herbs, and certain beverages such as tea and coffee $[95,96,98,99]$. In $\mathrm{AD}$, polyphenols may reduce the levels of $\mathrm{A} \beta[95,96]$. Curcumin is derived from the turmeric root and is considered a beneficial polyphenol with strong antioxidant properties; reports have indicated that curcumin may have benefits in several degenerative diseases relating to aging, such as AD [100,101]. Since polyphenols and flavonoids are found in fruits and vegetables, the daily consumption of a healthy diet is considered a useful preventive approach against neurodegenerative disorders [102]. Similarly, nuts, including walnuts, almonds, and hazelnuts, offer essential phytochemicals and micronutrients/macronutrients, which can have a positive impact on $\mathrm{AD}$ pathogenesis, including processes involving tau phosphorylation, amyloidogenesis, cholinergic pathways, and OS [103].

\section{Huntington's Disease (HD)}

Huntington's disease is a genetic neurodegenerative disorder characterized by the selective degeneration of neurons. This degeneration results in progressive disabilities, including motor dysfunction and both cognitive and psychiatric deficiencies [104-106]. HD is associated with polyglutamine-expansion; thus, the disease primarily impacts the cerebral cortex and striatum $[107,108]$. Key symptoms include motor dysfunction, progressive cognitive decline, and psychiatric disturbances $[109,110]$. Primarily, HD is known to impact the corpus striatum and is characterized by cognitive/ motor deficits and unusual involuntary movements [111,112].

\section{Huntington's disease and oxidative stress}

Huntington's disease is caused by a repeat expansion of cytosine-adenine-guanine (CAG) in the huntingtin gene $[105,113,114]$. The mutant huntingtin protein (mHTT) leads to neuronal dysfunction before ultimately causing cell death due to excitotoxicity, transcriptional deficiencies, inflammation, oxidative damage, mitochondrial dysfunction, and apoptosis $[112,115,116]$. Excessive mHTT accumulation is responsible for causing an unusually high production of ROS, along with the concomitant mitochondrial OS, in neurons [40,117]. According to several reports, neuronal degeneration mediated by mitochondrial dysfunction and OS is a major contributing factor in HD [107,118]. In addition, OS promulgates mHTT aggregation and cell death by replicating proteasomal abnormalities $[119,120]$. The heightened production of free radicals also inhibits the production of energy and proper mitochondrial function. Similarly, impairments in metabolism have been shown to cause excitotoxic damage [121]. In HD, oxidative damage has been observed in proteins, lipids, and DNA [122]. In this regard, the inadequate repair of damaged DNA is believed to be a primary contributing factor to the repeat expansion of CAG [123]. In addition, HD patients have been reported to have increased levels of OS markers, along with a decrease in antioxidant status compared with healthy participants [124]. In summary, accumulation of mHTT protein, 
impairment in the electron transport chain and mitochondrial dysfunction, imbalance in oxidant-antioxidant status, higher lipid concentration and high energy requirement, and poor antioxidant status generates oxidative stress, particularly ROS in HD. Enhanced oxidative alterations to mHTT protein leads to protein misfolding and protein aggregation which in turn causes exacerbation of neurodegeneration in HD.

\section{Huntington's disease and nutrients}

According to various studies (Table 1 ), vitamin $B_{5}$ deficiency may cause dementia and neurodegeneration in HD patients, and treatments that include $B_{5}$ may help prevent the progression of HD [105]. Plant-derived polyphenols are ubiquitous compounds characterized by numerous pharmacological properties, including antioxidant, anti-inflammatory, mitochondrial protective, and anti-apoptotic activities [95,42]. Polyphenols are also known to improve cognitive function and delay and/ or prevent the onset of certain neurodegenerative diseases, including HD $[43,125]$. In rodents, olive oil has been shown to decrease oxidative damage in 3-nitropropionic acid-induced HD cases [126]. Studies showed that both hydroxytyrosol and extra virgin olive oil acted as robust brain antioxidants [127]. In addition, other studies have reported that green tea plays a role in preventing early-stage events associated with HD pathogenesis, including Huntington's misfolding $[128,129]$. Similarly, the combination of fish oil and quercetin has been reported to offer protection against HD induced by 3-nitropropionic acid [130].

\section{Parkinson's disease}

Parkinson's disease is a progressive disorder characterized by various motor-related symptoms, including slow movements, body tremors, and rigidity $[131,132]$. In general, motor symptoms related to PD first manifest after the death of over $60 \%$ of dopaminergic neurons within the brain $[133,134]$. Indeed, the pathological hallmarks of PD include the generation of Lewy bodies and the erosion of dopaminergic neurons in the substantia nigra pars compacta [135-137]. According to a growing body of evidence, neuroinflammation plays a significant role in the pathogenesis of $\mathrm{PD}$, which could serve as a target of neuroprotection $[138,139]$. Products of dopamine quinones and oxidation also reportedly lead to PD-related neurodegeneration $[140,141]$. Various exogenous causes have been implicated in the etiology of PD, including the excessive use of pesticides/herbicides, exposure to carbon disulfide and monoxide, plant-derived toxins, and both viral and bacterial infections [20]. In addition, aging appears to be a factor, ceasing the normal cellular processes which in turn leading to the increased degeneration of dopaminergic neurons [142].

\section{Parkinson's disease and oxidative stress}

Oxidative stress and mitochondrial dysfunction play an important role in exacerbating PD [143-146]. Indeed, cellular inflammation and stress are known to cause reactive astrogliosis, which in turn leads to the generation of astrocytic
ROS [147]. In this context, ROS are regarded as important modulators of PD $[148,149]$. At the same time, dopaminergic neurons of the substantia nigra are especially susceptible to processes of degeneration in PD [141,150]. In addition, increased levels of oxidized proteins and lipids have been observed in PD patients [19]. It is notable that among the organelles capable of generating ROS, mitochondria account for over $90 \%$ of all ROS production [151]. During their lifespan, dopamine neurons are constantly exposed to RNS and ROS from metabolic processes localized to the cytosol [152154]. Being a comparatively unstable molecule, dopamine itself can produce ROS by undergoing auto-oxidation within the nigrostriatal tract system, indicating that oxidation may progress with aging $[155,156]$. In summary, accumulation of alpha-synuclein protein, impaired respiratory chain and somatic mitochondrial DNA mutations, iron accumulation, enhanced dopamine metabolism, increase in malondialdehyde and hydroperoxides in the substantia nigra, hydroxyl radical accumulation, and poor antioxidant status generates oxidative stress, particularly ROS in PD. Enhanced oxidative alterations to $\alpha$-synuclein protein lead to protein misfolding and protein aggregation which in turn causes exacerbation of neurodegeneration and destruction of neuronal cells and death of dopaminergic neurons in PD [22]. The destruction of the cells and the reduced dopaminergic transmission in the substantia nigra leads to progressive loss of muscular coordination and balance in PD.

\section{Parkinson's disease and nutrients}

It has been reported that PD can be effectively managed with nutritional supplementation, particularly dietary interventions involving foods containing vitamins $B$ and D, as well as coenzyme Q and omega-3 fatty acids (Table 1) [157-159]. Foods that have been established to reduce the progression rate of PD include fresh fruits and vegetables, nuts and seeds, olive oil, fish (non-fried), spices, fresh herbs, and coconut oil [160]. In contrast, foods associated with faster PD progression include fried foods, both non-diet and diet soda, ice cream, beef, cheese, canned fruits/vegetables, and yogurt [160]. Unlike iron supplements, nutritional supplements containing coenzyme Q10 and fish oil have been linked to a lower progression of PD [160]. In addition, tea intake has been linked to a lower risk of developing PD. Indeed, it has been reported that people who consume at least one cup of black tea daily have a decreased risk of developing PD [161].

A deficiency in vitamin $B_{12}$ is also known to be a key factor that causes comorbidity among PD patients owing to the heightened rate of bacterial overgrowth that occurs in the intestines of $25 \%-54 \%$ of PD patients [90,162,163]. Notably, vitamin $B_{12}$ is primarily sourced from animals [98]. In one study of 72 PD patients, with a follow-up period of nine years, higher consumption of vitamin $\mathrm{B}_{6}$ was linked to a considerably decreased risk of PD progression [88]. Furthermore, the B vitamin, niacin (vitamin $B_{3}$ ), is known to lower oxidative stress. 
Given that PD physiopathology is associated with a failure of cellular energy and mitochondrial dysfunction, niacin may perform antioxidant and neuroprotective functions at low doses owing to its role in several metabolic pathways $[164,165]$. Sources of B vitamins include whole grains, legumes, bananas, meat, and potatoes [98].

Vitamin C also plays a key role in decreasing ROS and lipid peroxidation, in addition to being instrumental for the regeneration of other key antioxidants [166,167]. A study comprising 1,000 PD patients found that the intake of vitamin C decreased the risk of PD progression [168]. Primary sources of vitamin C include fruits, paprika, citrus foods, and vegetables [98]. In addition, multiple clinical studies have reported that concentrations of serum vitamin D are negatively correlated with the severity and risk of PD $[169,170]$. Vitamin $\mathrm{D}_{3}$ is known to prevent oxidative stress, lower the production of free radicals, and reduce neurotoxicity through the enhancement of autophagy signaling pathways, thereby having a positive effect in PD patients [171-173]. One study consisting of 2,866 patients with Parkinson's disease and 2,734 healthy controls observed that increased serum vitamin $D$ levels reduced the severity of progression of PD [174]. A regular intake of foods rich in vitamin E may also defer the development or even lower the risk of PD [175]. In fact, vitamin $E$ is a scavenger of several ROS and serves to reduce their reactivity and toxicity [79,175-177]. A study that administered a combination of vitamins $\mathrm{C}$ and $\mathrm{E}$ to patients in the early stages of $\mathrm{PD}$ found that the vitamin regimen slowed the progression of PD [178].

Increased polyunsaturated fattyacids(PUFAs) consumption is inversely correlated with PD [179]. Omega-3 fatty acids act as free radical scavengers and reduce ROS formation [180]. They also decrease the chemotaxis of monocytes and neutrophils and curb the formation of pro-inflammatory cytokines [175,181,182]. A cohort study consisting of 5,000 individuals found that a high intake of omega- 3 fatty acids reduced the risk of PD [180]. The sources of Omega-3 fatty acids include fish oils, cold-water fish, flaxseed oil, walnuts, edible seeds, and other dietary supplements [98]. On the other hand, polyphenols demonstrate powerful anti-inflammatory and antioxidant properties [95]. Considering the role of OS and inflammation in the onset and progression of PD, it has been found that dietary polyphenols such as catechins, anthocyanins, resveratrol, theaflavins, and curcumin may offer significant therapeutic benefit in PD [183,184]. Owing to their biological impacts, including as antioxidative, antiapoptotic, and anti-inflammatory agents, as well as their lipid-reducing traits, flavonoids may impart a wide range of health benefits, including diminished risk of PD [97,185-187]. A study of 130,000 participants showed that a high intake of flavonoids reduced the risk of PD [188]. Common flavonoid sources include berries, onions, parsley, all citrus fruits, dark chocolate, red wine, green/black tea, and Ginkgo biloba [189].

In addition, several preclinical studies involving animals have demonstrated the advantages of probiotics in preventing and treating disorders of the CNS [190]. A study comprising 60 PD patients thatwere administered a daily probiotic for 12 weeks found that the probiotic reduced the risk of PD progression [191]. In this regard, supplementation, involving probiotics, has shown a wide range of positive impacts on metabolic profiles/ symptoms, thereby having the potential to significantly benefit PD patients [191]. Foods with high prebiotic content include artichokes, bamboo shoots, asparagus, bananas, barley, black pepper, chicory coffee, dark beets, chocolate, broccoli, fennel root, endive, mustard greens, Jerusalem artichokes, ginger, jicama, tomatoes, yacón, leeks, and legumes [98].

\section{Amyotrophic Lateral Sclerosis (ALS)}

Amyotrophic lateral sclerosis is an irreversible neurodegenerative disorder that quickly progresses and causes the erosion of motor neurons not only within the brain but also throughout the spinal cord [192-194]. In addition, ALS is accompanied by the reduction and dysfunction of upper motor neurons $[48,195,196]$. ALS leads to the progressive but selective erosion of spinal, bulbar, and cortical motoneurons, which results in speech loss, progressive paralysis, difficulty in swallowing, and several respiratory malfunctions. Ultimately, ALS is fatal, and the time to death is related to the rate of progression [197,198]. As with other neurodegenerative disorders, neuroinflammation is frequently found in ALS [199]. ALS is characterized by inflammation related to astroglia/microglia, macrophages, and pro-inflammatory peripheral lymphocytes [200]. Evidence has shown that several genetic mutations are associated with ALS and amplify this neuroinflammation, which is evidence for immune dysregulation in ALS pathogenesis [199,201].

\section{ALS and oxidative stress}

It has been discovered that ALS patients have mutations in the gene encoding the antioxidant enzyme superoxide dismutase 1 (SOD1) [202]. Mutant SOD1 leads to aggregation in motor neurons within the CNS [193]. Other causes include oxidative stress, neuroinflammation, glutamate excitotoxicity, changes in neurofilaments, mitochondrial degeneration and damage, protein aggregation, apoptosis, and deficiencies in factors related to growth [46,203-205]. Owing to the accumulation of dysfunctional mitochondria within the motor neurons impacted by the sporadic and genetic types of ALS, there is a clear indication that a failure to maintain healthy mitochondria exacerbates ALS [206,207]. Among ALS patients, OS has been linked to the degeneration of skeletal muscles and motor neurons [208,209]. Indeed, in conjunction with mitochondrial dysfunction, ROS is considered a major cause of ALS. It is also noteworthy that OS not only raises overall RNS/ROS formation but also impacts the structure and conformation of various proteins, which then causes abnormal protein accumulation [210]. Oxidative stress biomarkers in CNS regions of paramount significance in the context of ALS are also indicative of their involvement in the degeneration 
of motor neurons [211]. Mitochondrial dysfunction associated with ALS is known to manifest in numerous ways, including as defective oxidative phosphorylation, ROS production, deficient calcium buffering, and problematic mitochondria dynamics [211]. Moreover, barring the issue of RNA toxicity, mitochondrial dysfunction appears to be correlated with all mechanisms of the toxicity characterizing ALS, such as deficient axonal transport, the erosion of homeostasis, and excitotoxicity [211]. Heightened levels of damage associated with ROS and RNS have been observed in ALS [210]. In addition, increased levels of ROS have been reported in the lymphoblasts of familial cases of ALS [212]. In summary, glutamate-induced excitotoxicity, mitochondrial dysfunction generates oxidative stress, particularly ROS in ALS. Enhanced oxidativealterations to SOD 1 protein lead to protein misfolding and protein degradation which in turn causes exacerbation of neurodegeneration in ALS [22]. The destruction of motor neurons leads to the muscle weakness in ALS.

\section{ALS and nutrients}

A higher intake of vegetables and fruits is negatively correlated with ALS [213]. In addition to being an efficacious scavenger of free radicals, vitamin $\mathrm{C}$ also modulates the metabolism of neurons by lowering the consumption of glucose during glutamatergic synaptic activity, while also fostering an increase of neuronal lactate, which is consistent with the reduced ratio of lactate to pyruvate observed in ALS patients (Table 1) [214]. A study in rodents administered with vitamin $\mathrm{C}$ before and after the onset of ALS found that the former regimen resulted in longer survival by $62 \%$ [215]. It has also been demonstrated that vitamin D can affect several facets of the pathology of ALS [216], including reducing the expression of biomarkers linked with neuroinflammation and OS [217].

Fiber, vitamin E, and omega-3 fatty acids can also potentially impart lasting benefits in ALS [193]. A study comprising 132 ALS patients and 220 healthy controls showed that high consumption of vitamin $\mathrm{E}$, in conjunction with omega-3 fatty acids, reduced the risk of developing ALS by as much as $50 \%-$ $60 \%$ [218]. Indeed, the results another study indicated that the participants who consumed vitamin E supplements had a significantly lower risk of death caused by ALS than those who did not, thus underscoring the potential efficacy of vitamin $\mathrm{E}$ in the prevention of ALS [219]. In addition, zinc is also known to perform key functions in various pathological mechanisms traditionally correlated with ALS [220]. Cannabinoids have also been postulated as therapeutic options for ALS owing to their anti-inflammatory, antioxidant, and anti-excitotoxicity properties [221,222]. Cannabinoid sources include flax seeds, hemp oil, seeds, eggs, and anchovies [223].

\section{Neurodegenerative disorders and nutraceuticals}

The following table 1 displays the beneficial effects and the mechanisms of the nutraceuticals suggested for prevention and treatment of neurodegenerative diseases.

\section{Conclusion}

Although major neurodegenerative disorders such as $\mathrm{AD}, \mathrm{HD}, \mathrm{PD}$, and ALS are linked to multiple pathophysiologic processes as well as etiologies, it is evident that OS and, in particular, the production of ROS, are significant factors. In general, a proper balance between antioxidants and ROS is necessary for cells to function properly, and OS has been attributed to neuroinflammation, dopamine degeneration, and mitochondria dysfunction. Meanwhile, the onset of OS generates ROS, which can have damaging impacts on the neurons within the brain, resulting in neurodegeneration. Similarly, mitochondrial dysfunction has been found to exacerbate the imbalance between antioxidants and ROS within the cellular environment. The excess ROS production leads to neurodegenerative disorders. Enhanced oxidative alterations to $\beta$-amyloid proteins in $\mathrm{AD}, \alpha$-synuclein proteins in PD, mHTT proteins in HD, and SOD 1 proteins in ALS lead to protein misfolding and protein aggregation which in turn causes exacerbation of neurodegeneration and destruction of neuronal cells. Given that OS can begin at a young age, the role of dietary intervention assumes great importance in preventing or deferring the advancement of neurodegenerative disorders. Indeed, increasing evidence has shown that antioxidants constitute a promising approach to prevent the occurrence of neurodegenerative diseases. Intake of balanced nutrients and efficient antioxidants may also facilitate the treatment strategies for patients of Alzheimer's disease, Huntington's disease, Parkinson's disease, Amyotrophic lateral sclerosis diseases, and other neurodegenerative diseases.

\section{References}

1. Kim GH, Kim JE, Rhie SJ, Yoon S. The role of oxidative stress in neurodegenerative diseases. Exp Neurobiol. 2015; 24: 325-340. PubMed: https://www.ncbi.nlm.nih.gov/pubmed/26713080

2. Salim S. Oxidative stress and the central nervous system. J Pharmacol Exp Ther. 2017; 360: 201-205

PubMed: https://www.ncbi.nlm.nih.gov/pubmed/27754930

3. Paradies G, Petrosillo G, Paradies V, Ruggiero FM. Mitochondria dysfunction in brain aging: Role of oxidative stress and cardiolipin. Neurochem Int. 2011; 58: 447-457.

PubMed: https://www.ncbi.nlm.nih.gov/pubmed/21215780

4. Hassan W, Silva CEB, Mohammadzai IU, da Rocha JBT, LandeiraFernandez J. Association of oxidative stress to the genesis of anxiety: Implications for possible therapeutic interventions. Curr Neuropharmacol. 2014; 12: 120-139.

PubMed: https://www.ncbi.nlm.nih.gov/pubmed/24669207

5. Liu Z, Ren Z, Zhang J, Chuang CC, Kandaswamy E, et al. Role of ROS and nutritional antioxidants in human diseases. Front Physiol. 2018; 9: 477. PubMed: https://www.ncbi.nlm.nih.gov/pubmed/29867535

6. Newsholme P, Cruzat VF, Keane KN, Carlessi R, de Bittencourt PIH. Molecular mechanisms of ROS production and oxidative stress in diabetes. Biochem J. 2016; 473: 4527-4550.

PubMed: https://www.ncbi.nlm.nih.gov/pubmed/27941030

7. Pizzino G, Irrera N, Cucinotta M, Pallio G, Mannino F, et al. Oxidative stress: Harms and benefits for human health. Oxid Med Cell Longev. 2017; 2017: 8416763.

PubMed: https://www.ncbi.nlm.nih.gov/pubmed/28819546 
8. Birben E, Sahiner UM, Sackesen C, Erzurum S, Kalayci O. Oxidative stress and antioxidant defense. World Allergy Organ J. 2012; 5: 9-19. PubMed: https://www.ncbi.nlm.nih.gov/pubmed/23268465

9. Sharma P, Jha AB, Dubey RS, Pessarakli M. Reactive oxygen species, oxidative damage, and antioxidative defense mechanism in plants under stressful conditions. J Bot. 2012; 2012: 217037.

PubMed: https://www.ncbi.nlm.nih.gov/pubmed/27269705

10. Collin F, Cheignon C, Hureau C. Oxidative stress as a biomarker for Alzheimer's disease. Biomarkers in Med. 2018; 12: 201-203.

PubMed: https://www.ncbi.nlm.nih.gov/pubmed/29436240

11. Feng Ye, Wang X. Antioxidant therapies for Alzheimer's disease. Oxid Med Cell Longev. 2012; 2012: 472932.

PubMed: https://www.ncbi.nlm.nih.gov/pubmed/22888398

12. Oliver DMA, Hemachandra Reddy P. Small molecules as therapeutic drugs for Alzheimer's disease. Mol Cell Neurosci. 2019; 96: 47-62.

PubMed: https://www.ncbi.nlm.nih.gov/pubmed/30877034

13. Panahi Y, Rajaee SM, Johnston TP, Sahebkar A. Neuroprotective effects of antioxidants in the management of neurodegenerative disorders: $A$ literature review. J Cell Biochem. 2019; 120: 2742-2748.

PubMed: https://www.ncbi.nlm.nih.gov/pubmed/29219206

14. Bjorklund G, Chirumbolo S. Role of oxidative stress and antioxidants in daily nutrition and human health. Nutrition. 2017; 33: 311-321. PubMed: https://www.ncbi.nlm.nih.gov/pubmed/27746034

15. Basambombo LL. Carmichael PH, Cote S, Laurin D. Use of vitamin $\mathrm{E}$ and $\mathrm{C}$ supplements for the prevention of cognitive decline. Ann Pharmacother. 2017; 51: 118-124.

PubMed: https://www.ncbi.nlm.nih.gov/pubmed/27708183

16. Visioli F, Burgos-Ramos E. Selected micronutrients in cognitive decline prevention and therapy. Mol Neurobiol. 2016; 53: 4083-4093.

PubMed: https://www.ncbi.nlm.nih.gov/pubmed/26198569

17. Sisein EA. Biochemistry of free radicals and antioxidants. Acad $J$ Biosci. 2014; 2: 110-118.

18. Poljsak B, Dušan Š, Milisav I. Achieving the balance between ROS and antioxidants: When to use the synthetic antioxidants. Oxid Med Cell Longev. 2013; 2013: 956792.

PubMed: https://www.ncbi.nlm.nih.gov/pubmed/23738047

19. Collin F. Chemical basis of reactive oxygen species reactivity and involvement in neurodegenerative diseases. Int J MolSci. 2019;20:2407. PubMed: https://www.ncbi.nlm.nih.gov/pubmed/31096608

20. Singh A, Kukreti R, Saso L, Kukreti S. Oxidative stress: A key modulator in neurodegenerative diseases. Molecules. 2019; 24.

PubMed: https://www.ncbi.nlm.nih.gov/pubmed/31013638

21. Kawamura T, Muraoka I. Exercise-induced oxidative stress and the effects of antioxidant intake from a physiological viewpoint Antioxidants. 2018; 7: 119.

PubMed: https://www.ncbi.nlm.nih.gov/pubmed/30189660

22. Johri A, Beal MF. Antioxidants in Huntington's disease. Biochim Biophys Acta. 2012; 1822: 664-674.

PubMed: https://www.ncbi.nlm.nih.gov/pubmed/22138129

23. Kovacic P, Pozos RS, Somanathan R, Shangari N, O'Brien PJ. Mechanism of mitochondrial uncouplers, inhibitors, and toxins: Focus on electron transfer, free radicals, and structure-activity relationships. Curr Med Chem. 2005; 12: 2601-2623.

PubMed: https://www.ncbi.nlm.nih.gov/pubmed/16248817

24. Chouchani ET, Pell VR, James A, Work LM, Saeb-Parsy K, et al. A unifying mechanism for mitochondrial superoxide production during ischemia-reperfusion injury. Cell Metab. 2016; 23: 254-263.

PubMed: https://www.ncbi.nlm.nih.gov/pubmed/26777689
25. Rahal A, Kumar A, Singh V, Yadav B, Tiwari R, et al. Oxidative stress, prooxidants, and antioxidants: The interplay. BioMed Res Int. 2014 2014: 761264

PubMed: https://www.ncbi.nlm.nih.gov/pubmed/24587990

26. Buico A, Cassino C, Ravera M, Betta P, Osella D. Oxidative stress and total antioxidant capacity in human plasma. Redox Report: Communications in Free Radical Research. 2009; 14: 125-131.

27. Cui $\mathrm{H}$, Kong $\mathrm{Y}$, Zhang $\mathrm{H}$. Oxidative stress, mitochondrial dysfunction, and aging. J Signal Transduction. 2012; 2012: 646354.

28. Jezek J, Cooper KF, Strich R. Reactive oxygen species and mitochondrial dynamics: The yin and yang of mitochondrial dysfunction and cancer progression. Antioxidants (Basel). 2018; 7: 13

PubMed: https://www.ncbi.nlm.nih.gov/pubmed/29337889

29. Zhou L, Zhang Q, Zhang P, Sun L, Peng C, et al. c-Abl-mediated Drp1 phosphorylation promotes oxidative stress-induced mitochondrial fragmentation and neuronal cell death. Cell Death Dis. 2017; 8: e3117. PubMed: https://www.ncbi.nlm.nih.gov/pubmed/29022905

30. Mehta $V$, Desai $N$, Perwez A, Nemade D, Dawoodi $S$, et al. ACE Alzheimer's: The role of vitamin A, C and $E(A C E)$ in oxidative stress induced Alzheimer's disease. J Med Res Innov. 2018; 2.

31. Butterfield DA, Kanski J. Brain protein oxidation in age-related neurodegenerative disorders that are associated with aggregated proteins. Mech Ageing Dev. 2001; 122: 945-962.

PubMed: https://www.ncbi.nlm.nih.gov/pubmed/11348660

32. Forni C, Facchiano F, Bartoli M, Pieretti S, Facchiano A, et al. Beneficial role of phytochemicals on oxidative stress and age-related diseases. BioMed Res Int. 2019; 2019: 8748253.

PubMed: https://www.ncbi.nlm.nih.gov/pubmed/31080832

33. Tiwari SC, Soni RM. Alzheimer's disease pathology and oxidative stress: Possible therapeutic options. J Alzheimers Dis Parkinsonism. 2014; 4.

34. de Mello AH, Costa AB, Engel JDG, Rezin GT. Mitochondrial dysfunction in obesity. Life Sci. 2018; 192: 26-32.

PubMed: https://www.ncbi.nlm.nih.gov/pubmed/29155300

35. Jha SK, Jha NK, Kumar D, Ambasta RK, Kumar P. Linking mitochondria dysfunction, metabolic syndrome and stress signaling in Neurodegeneration. Molecular Basis of Disease. 2017; 1863:1132-1146. PubMed: https://www.ncbi.nlm.nih.gov/pubmed/27345267

36. Juarez Olguín H, Calderon Guzman D, Hernandez García E, Barragan Mejía G. The role of dopamine and its dysfunction as a consequence of oxidative stress. Oxid Med Cell Longev. 2016; 2016: 9730467. PubMed: https://www.ncbi.nlm.nih.gov/pubmed/26770661

37. Federico A, Cardaioli E, Da Pozzo P, Formichi P, Gallus GN, et al. Mitochondria, oxidative stress and neurodegeneration. I Neurol Sci. 2012; 322: 254-262

PubMed: https://www.ncbi.nlm.nih.gov/pubmed/22669122

38. Song P, Zou MH. Roles of reactive oxygen species in physiology and pathology. In: Wang $\mathrm{H}$, Patterson $\mathrm{C}$, editors. Atherosclerosis: Risks, Mechanisms, and Therapies. Hoboken, NJ: John Wiley \& Sons Inc. 2015; 379-392.

39. Carocci A, Catalano A, Sinicropi MS, Genchi G. Oxidative stress and neurodegeneration:Theinvolvementofiron. BioMetals. 2018;31:715-735. PubMed: https://www.ncbi.nlm.nih.gov/pubmed/30014355

40. Essa MM, Moghadas M, Ba-Omar T, Qoronfleh MW, Guillemin GJ, et al. Protective effects of antioxidants in Huntington's disease: An extensive review. Neurotox Res. 2019; 35: 739-774.

PubMed: https://www.ncbi.nlm.nih.gov/pubmed/30632085 
41. Ian SH, Karri V, Tay NWR, Chang KH, Ah HY, et al. Emerging pathways to neurodegeneration: Dissecting the critical molecular mechanisms in Alzheimer's disease, Parkinson's disease. Biomed Pharmacother 2019; 111: 765-777.

PubMed: https://www.ncbi.nlm.nih.gov/pubmed/30612001

42. Manivasagam T, Thenmozhi, AJ, Bharathi MD, Sumathi T, Saravanababu C, et al. Polyphenols and Huntington's disease. Food for Huntington's Disease. Nova Science Publishers, 2018; 39-62.

43. Teixeira J, Chavarria D, Borges F, Wojtczak L, Wieckowski M, et al. Dietary polyphenols and mitochondrial function: Role in health and disease. Curr Med Chem. 2019; 26: 3376-3407.

PubMed: https://www.ncbi.nlm.nih.gov/pubmed/28554320

44. Sbodio JI,Snyder SH, Paul BD. Redox mechanisms in neurodegeneration: From disease outcomes to therapeutic opportunities. Antioxid Redox Signaling. 2019; 30: 1450-1499.

PubMed: https://www.ncbi.nlm.nih.gov/pubmed/29634350

45. Butterfield DA, Halliwell B. Oxidative stress, dysfunctional glucose metabolismand Alzheimer disease. Nat RevNeurosci. 2019;20:148-160. PubMed: https://www.ncbi.nlm.nih.gov/pubmed/30737462

46. Kumar K, Kumar A, Keegan RK, Deshmukh R. Recent advances in the neurobiology and neuropharmacology of Alzheimer's disease. Biomed Pharmacother. 2018; 98: 297-307.

PubMed: https://www.ncbi.nlm.nih.gov/pubmed/29274586

47. Bashir H. Emerging therapies in Huntington's disease, Expert Rev Neurother. 2019; 1-13

48. Zhou J, Li A, Jun Li X, Yi J. Dysregulated mitochondrial Ca2+ and ROS signaling in skeletal muscle of ALS mouse model. Arch Biochem Biophys. 2019a; 663: 249-258.

PubMed: https://www.ncbi.nlm.nih.gov/pubmed/30682329

49. Mangrulkar S, Chaple DR. Pharmacological assessments of polyphenolic extract of cymbopogon citratus leaves in rodent model of Parkinson's disease. J Drug Delivery Ther. 2019; 9: 311-315

50. Pajarillo E, Rizor, A, Lee J, Aschner M, Lee E. The role of posttranslational modifications of alpha-synuclein and LRRK2 in Parkinson's disease: Potential contributions of environmental factors. Biochim Biophys Acta Mol Basis Dis. 2019; 1865: 1992-2000.

PubMed: https://www.ncbi.nlm.nih.gov/pubmed/30481588

51. Escher CM, Sannemann L, Jessen F. Stress and Alzheimer's disease. J Neural Transm. 2019; 126: 1155-1161.

PubMed: https://www.ncbi.nlm.nih.gov/pubmed/30788601

52. Liu $Y$, Nguyen M, Robert A, Meunier B. Metal ions in Alzheimer's disease: A key role or not? Acc Chem Res. 2019; 52: 2026-2035. PubMed: https://www.ncbi.nlm.nih.gov/pubmed/31274278

53. Timmers M, Tesseur I, Bogert J, Zetterberg H, Blennow K, et al. Relevance of the interplay between amyloid and tau for cognitive impairment in early Alzheimer's disease. Neurobiol Aging. 2019; 79: 131-141. PubMed: https://www.ncbi.nlm.nih.gov/pubmed/31055223

54. Tublin JM, Adelstein JM, del Monte F, Combs CK, Wold LE. Getting to the heart of Alzheimer disease. Circ Res. 2019; 124: 142-149. PubMed: https://www.ncbi.nlm.nih.gov/pubmed/30605407

55. Gao Y, Tan L, Yu JT, Tan L. Tau in Alzheimer's disease: Mechanisms and therapeutic strategies. Curr Alzheimer Res. 2018; 15: 283-300. PubMed: https://www.ncbi.nlm.nih.gov/pubmed/28413986

56. Ozben T, Ozben S. Neuro-inflammation and anti-inflammatory treatment options for Alzheimer's disease. Clin Biochem. 2019; 72: 87-89. PubMed: https://www.ncbi.nlm.nih.gov/pubmed/30954437

57. Sun B, Li W, Zhu C. Clinical research on Alzheimer's disease: Progress and perspectives. Neurosci Bull. 2018; 34: 1111-1118. PubMed: https://www.ncbi.nlm.nih.gov/pubmed/29956105

58. Liddelow SA. Modern approaches to investigating non-neuronal aspects of Alzheimer's disease. FASEB J. 2019; 33: 1528-1535. PubMed: https://www.ncbi.nlm.nih.gov/pubmed/30703873

59. Henstridge CM, Hyman BT, Spires-Jones TL. Beyond the neuroncellular interactions early in Alzheimer disease pathogenesis. Nat Rev Neurosci. 2019; 20: 94-108.

PubMed: https://www.ncbi.nlm.nih.gov/pubmed/30643230

60. Alzoubi KH, Hasan ZA, Khabour OF, Mayyas FA, Al Yacoub ON, et al. The effect of high-fat diet on seizure threshold in rats: Role of oxidative stress. Physiol Behav. 2018; 196: 1-7.

PubMed: https://www.ncbi.nlm.nih.gov/pubmed/30149086

61. Morzelle MC, Salgado JM, Massarioli AP, Bachiega P, De Oliveira Rios $A$, et al. Potential benefits of phenolics from pomegranate pulp and peel in Alzheimer's disease: Antioxidant activity and inhibition of acetylcholinesterase. J Food Bioact. 2019; 5: 136-141.

62. Grundman M. Tau based therapeutics: Alternative approaches in the war on Alzheimer's disease. J Prev Alz Dis. 2019; 6: 151-152. PubMed: https://www.ncbi.nlm.nih.gov/pubmed/31062822

63. Busche MA, Wegmann S, Dujardin S, Commins C, Schiantarelli J, et al. Tau impairs neural circuits, dominating amyloid- $\beta$ effects, in Alzheimer models in vivo. Nat Neurosci. 2019; 22: 57-64.

PubMed: https://www.ncbi.nlm.nih.gov/pubmed/30559471

64. Perez Ortiz JM, Swerdlow RH. Mitochondrial dysfunction in Alzheimer's disease: Role in pathogenesis and novel therapeutic opportunities. $\mathrm{Br}$ J Pharmacol. 2019; 176: 3489-3507.

PubMed: https://www.ncbi.nlm.nih.gov/pubmed/30675901

65. Nakabeppu Y. Molecular pathophysiology of insulin depletion, mitochondrial dysfunction, and oxidative stress in Alzheimer's disease brain. Adv Exp Med Biol. 2019; 1128:27-44.

PubMed: https://www.ncbi.nlm.nih.gov/pubmed/31062324

66. Wee M, Chegini F, Power JHT, Majd S. Tau positive neurons show marked mitochondrial loss and nuclear degradation in Alzheimer's disease. Curr Alzheimer Res. 2018; 15: 928-937.

PubMed: https://www.ncbi.nlm.nih.gov/pubmed/29895248

67. MartinsRN, VillemagneV,SohrabiHR,ChatterjeeP,ShahT,etal.Alzheimer's disease: A journey from amyloid peptides and oxidative stress, to biomarker technologies and disease prevention strategies - gains from AIBL and DIAN cohort studies. J Alzheimers Dis. 2018; 62: 965-992. PubMed: https://www.ncbi.nlm.nih.gov/pubmed/29562546

68. Zetterberg $\mathrm{H}$, Schott JM. Biomarkers for Alzheimer's disease beyond amyloid and tau. Nat Med. 2019; 25: 201-203.

PubMed: https://www.ncbi.nlm.nih.gov/pubmed/30728536

69. Bennett RE, De Vos SL, Dujardin S, Corjuc B, Gor R, et al. Enhanced tau aggregation in the presence of amyloid $\beta$. Am J Pathol. 2017; 187 : 1601-1612.

PubMed: https://www.ncbi.nlm.nih.gov/pubmed/28500862

70. Lim YY, Maruff P, Pietrzak RH, Ames D, Ellis KA, et al. Effect of amyloid on memory and non-memory decline from preclinical to clinical Alzheimer's disease. Brain. 2014; 137: 221-231.

PubMed: https://www.ncbi.nlm.nih.gov/pubmed/24176981

71. Flannery PJ, Trushina E. Mitochondrial dynamics and transport in Alzheimer's disease. Mol Cell Neurosci. 2019; 98: 109-120. PubMed: https://www.ncbi.nlm.nih.gov/pubmed/31216425

72. Mosconi L. Effect of diet on hippocampal volume in a population at risk for Alzheimer's disease. Integrative Medicine Alert Atlanta. 2019; 22.

73. Power R, Prado-Cabrero A, Mulcahy R, Howard A, Nolan JM. The role 
of nutrition for the aging population: Implications for cognition and Alzheimer's disease. Annu Rev Food Sci Technol. 2019; 10: 619-639. PubMed: https://www.ncbi.nlm.nih.gov/pubmed/30908950

74. Cao L, Tan L, Wang HF, Jiang T, Zhu X, et al. Dietary patterns and risk of dementia: A systematic review and meta-analysis of cohort studies. Mol Neurobiol. 2016; 53: 6144-6154

PubMed: https://www.ncbi.nlm.nih.gov/pubmed/26553347

75. Grimm MOW, Mett J, Hartmann T. The impact of vitamin E and other fatsoluble vitamins on Alzheimer's disease. Int J Mol Sci. 2016; 17: 1785 PubMed: https://www.ncbi.nlm.nih.gov/pubmed/27792188

76. Niki E. Antioxidants: Basic principles, emerging concepts, and problems. Biomed J. 2014; 37: 106-111.

PubMed: https://www.ncbi.nlm.nih.gov/pubmed/24923567

77. Thapa A, Carroll NJ. Dietary modulation of oxidative stress in Alzheimer's disease. Int J Mol Sci. 2017; 18: 1583.

PubMed: https://www.ncbi.nlm.nih.gov/pubmed/28753984

78. Karantzoulis S, Galvin JE. Distinguishing Alzheimer"s disease from other major forms of dementia. Expert Rev Neurother. 2011; 11: 1579-1591. PubMed: https://www.ncbi.nlm.nih.gov/pubmed/3729743

79. Schirinzi T, Martella G, Imbriani P, Lazzaro GD, Franco D, et al. Dietary vitamin $\mathrm{E}$ as a protective factor for Parkinson's disease: Clinical and experimental evidence. Front Neurol. 2019; 10: 148.

PubMed: https://www.ncbi.nlm.nih.gov/pubmed/30863359

80. Annweiler C, Rolland Y, Schott AM, Blain H, Vellas B, et al. Higher vitamin $D$ dietary intake is associated with lower risk of Alzheimer's disease: A 7-year follow-up. J Gerontol, Ser A. 2012; 67: 1205-1211. PubMed: https://www.ncbi.nlm.nih.gov/pubmed/22503994

81. Harrison FE. A critical review of vitamin C for the prevention of agerelated cognitive decline and Alzheimer's disease. J Alzheimers Dis. 2012; 29: 711-726.

PubMed: https://www.ncbi.nlm.nih.gov/pubmed/22366772

82. Zandi PP, Anthony JC, Khachaturian AS. Reduced risk of Alzheimer disease in users of antioxidant vitamin supplements: The cache county study. Arch Neurol. 2004; 61: 82-88.

PubMed: https://www.ncbi.nlm.nih.gov/pubmed/14732624

83. Weber $\mathrm{P}$, Birringer $\mathrm{M}$, Blumberg J, Eggersdorfer M, Frank J. Humana Press, Cham. Vitamin E in Human Health. Nutrition and Health. 2019; 325-344.

84. Dong S, Huang X, Zhen J, Halm-Lutterodt NV, Wang J, et al. Dietary vitamin $E$ status dictates oxidative stress outcomes by modulating effects of fish oil supplementation in Alzheimer disease model APPswe/PS1dE9 mice. Mol Neurobiol. 2018; 55: 9204-9219. PubMed: https://www.ncbi.nlm.nih.gov/pubmed/29656360

85. Ulatowski LM, Manor D. Vitamin E and neurodegeneration. Neurobio Dis. 2015; 84: 78-83.

PubMed: https://www.ncbi.nlm.nih.gov/pubmed/25913028

86. Dong Y, Chen X, Liu Y, Shu Y, Chen T, et al. Do low-serum vitamin E levels increase the risk of Alzheimer disease in older people? Evidence from a meta-analysis of case-control studies. Int J Geriatr Psychiatry. 2018; 33: 257-263.

PubMed: https://www.ncbi.nlm.nih.gov/pubmed/28833475

87. Berti V, Murray J, Davies M, Spector N, Tsui WH, et al. Nutrient patterns and brain biomarkers of Alzheimer's disease in cognitively normal individuals. J Nutr Health Aging. 2015; 19: 413-423

PubMed: https://www.ncbi.nlm.nih.gov/pubmed/25809805

88. de Lau LML, Koudstaal PJ, Witteman JCM, Hofman A, Breteler MMB, et al. Dietary folate, vitamin B12, and vitamin $B_{6}$ and the risk of Parkinson disease. Neurology. 2006; 67: 315-318.

PubMed: https://www.ncbi.nlm.nih.gov/pubmed/16864826
89. Mitchell ES, Conus N, Kaput J. B vitamin polymorphisms and behavior: Evidence of associations with neurodevelopment, depression, schizophrenia, bipolar disorder and cognitive decline. Neurosci Biobehav Rev. 2014; 47: 307-320.

PubMed: https://www.ncbi.nlm.nih.gov/pubmed/25173634

90. Van de Lagemaat EE, de Groot LCPGM, van den Heuvel EGHM. Vitamin B12 in relation to oxidative stress: A systematic review. Nutrients. 2019; 11: 482.

PubMed: https://www.ncbi.nlm.nih.gov/pubmed/30823595

91. Celik E, Sanlier N. Effects of nutrient and bioactive food components on Alzheimer's disease and epigenetic. Crit Rev Food Sci Nutr. 2019; 59: 102-113.

PubMed: https://www.ncbi.nlm.nih.gov/pubmed/28799782

92. Hernando S, Requejo C, Herran E, Ruiz-Ortegade JA, MoreraHerrerase $T$, et al. Beneficial effects of $n-3$ polyunsaturated fatty acids administration in a partial lesion model of Parkinson's disease: The role of glia and NRf2 regulation. Neurobiol Dis. 2019; 121: 252-262. PubMed: https://www.ncbi.nlm.nih.gov/pubmed/30296616

93. Moloney $\mathrm{M}$. The role of Omega-3 fatty acids in the prevention of Alzheimer's disease in the early stages of disease presentation. $J$ Australian Traditional-Medicine Society. 2019; 25: 90-95.

94. Morris MC, Evans DA, Bienias JL, Tangney CC, Bennett DA, et al. Dietary fats and the risk of incident Alzheimer disease. Arch Neurol. 2003; 60: 194-200.

PubMed: https://www.ncbi.nlm.nih.gov/pubmed/12580703

95. Ataie A, Shadifar M, Ataee R. Polyphenolic antioxidants and neuronal regeneration. Basic Clin Neurosci. 2016; 7: 81-90. PubMed: https://www.ncbi.nlm.nih.gov/pubmed/27303602

96. Gaudreault R, Mousseau N. Mitigating Alzheimer's disease by natural polyphenols: A review. Curr Alzheimer Res. 2019; 16: 529-543. PubMed: https://www.ncbi.nlm.nih.gov/pubmed/30873922

97. Kostic AZ, Milincic DD, Gasic UM, Nedic N, Stanojevic S, et al Polyphenolic profile and antioxidant properties of bee-collected pollen from sunflower (Helianthus annuus L.) plant. LWT. 2019; 112.

98. Madireddy S, Madireddy S. The role of diet in maintaining strong brain health by taking the advantage of the gut-brain axis. J Food Nutr Res. 2019; 7: 41-50.

99. US. Department of Agriculture, Agricultural Research Service. USDA Food Composition Databases. 2018.

100. Farkhondeh T, Samarghandian S. Pourbagher-Shahri AM, Sedaghat M The impact of curcumin and its modified formulations on Alzheimer's disease. J Cell Physiol. 2019; 234: 16953-16965. PubMed: https://www.ncbi.nlm.nih.gov/pubmed/30847942

101. Lakey-Beitia J, Berrocal R, Rao KS, Durant AA. Polyphenols as therapeutic molecules in Alzheimer's disease through modulating amyloid pathways. Mol Neurobiol. 2015; 51: 466-479. PubMed: https://www.ncbi.nlm.nih.gov/pubmed/24826916

102. Solanki I, Parihar P, Mansuri ML, Parihar MS. Flavonoid-based therapies in the early management of neurodegenerative diseases. Adv Nutr. 2015; 6: 64-72.

PubMed: https://www.ncbi.nlm.nih.gov/pubmed/25593144

103. Gorji N, Moeini R, Memariani Z. Almond, hazelnut and walnut, three nuts for neuroprotection in Alzheimer's disease: A neuropharmacological reviewoftheirbioactiveconstituents. PharmacolRes.2017;129:115-127. PubMed: https://www.ncbi.nlm.nih.gov/pubmed/29208493

104. Kieburtz K, Reilmann R, Olanow CW. Huntington's disease: Current and future therapeutic prospects. Mov Disord. 2018; 33: 1033-1041. PubMed: https://www.ncbi.nlm.nih.gov/pubmed/29737569 
105. Patassini S, Begley1 P, Xu J, Church SJ, Kureishy N. Cerebral vitamin B5 (D-Pantothenic Acid) deficiency as a potential cause of metabolic perturbation and neurodegeneration in Huntington's disease. Metabolites. 2019; 9: 113.

PubMed: https://www.ncbi.nlm.nih.gov/pubmed/31212603

106. Tobore TO. Towards a comprehensive understanding of the contributions of mitochondrial dysfunction and oxidative stress in the pathogenesis and pathophysiology of Huntington's disease. $J$ Neurosci Res. 2019; 97: 1455-1468.

PubMed: https://www.ncbi.nlm.nih.gov/pubmed/31304621

107. Carmo C, Naia L, Lopes C, Rego AC. Mitochondrial Dysfunction in Huntington's disease. Adv Exp Med Biol. 2018; 1049: 59-83. PubMed: https://www.ncbi.nlm.nih.gov/pubmed/29427098

108. Khan F, Garg VK, Singh AK, Kumar T. Role of free radicals and certain antioxidants in the management of Huntington's disease: A review. $J$ Anal Pharm Res. 2018; 7: 386-392.

109. An P, Sun X. Huntington's disease: Current status and prospects. J Cell Signal. 2019; 4: 199.

110. Denis HL, Lamontagne-proulx, J, St-Amour, I, Mason S, Rowley J, et al. Platelet abnormalities in Huntington's disease. J Neurol Neurosurg Psychiatry. 2019; 90: 272-283.

PubMed: https://www.ncbi.nlm.nih.gov/pubmed/30567722

111. Bates GP, Dorsey R, Gusella, JF, Hayden MR, Kay C, et al. Huntington disease. Nat Rev Dis Primers. 2015; 1: 15005.

PubMed: https://www.ncbi.nlm.nih.gov/pubmed/27228260

112. McColgan P, Tabrizi SJ. Huntington's disease: A clinical review. Eur J Neurol. 2018; 25: 24-34.

PubMed: https://www.ncbi.nlm.nih.gov/pubmed/28817209

113. Biagioli M, Ferrari F, Mendenhall EM, Zhang Y, Erdin S, et al. Htt CAG repeat expansion confers pleiotropic gains of mutant Huntingtin function in chromatin regulation. Hum Mol Genet. 2015. 24: 2442-2457. PubMed: https://www.ncbi.nlm.nih.gov/pubmed/25574027

114. Mi Y, Gao X, Xu H, Cui Y, Zhang Y, et al. The Emerging roles of ferroptosis in Huntington's disease. NeuroMol Med. 2019; 21: 110-119. PubMed: https://www.ncbi.nlm.nih.gov/pubmed/30600476

115. Drombosky KW, Rode S, Kodali R, Jacob TC, Palladino MJ, et al. Mutational analysis implicates the amyloid fibril as the toxic entity in Huntington's disease. Neurobiol Dis. 2018; 120: 126-138. PubMed: https://www.ncbi.nlm.nih.gov/pubmed/30171891

116. Mason SL, Daws RE, Soreq E, Johnson EB, Scahill RI, et al. Predicting clinical diagnosis in Huntington's disease: An imaging polymarker. Ann Neurol. 2018; 83: 532-543

PubMed: https://www.ncbi.nlm.nih.gov/pubmed/29405351

117. Shacham T, Sharma N, Lederkremer GZ. Protein misfolding and ER stress in Huntington's disease. Front Mol Biosci. 2019; 6: 20. PubMed: https://www.ncbi.nlm.nih.gov/pubmed/31001537

118. Gaura V, Lavisse S, Payoux P, Goldman S, Verny C, et al. Association between motor symptoms and brain metabolism in early Huntington disease. JAMA Neurol. 2017; 74: 1088-1096.

PubMed: https://www.ncbi.nlm.nih.gov/pubmed/28672395

119. Byrne LM, Rodrigues FB. Johnson EB, Wijeratne PA, Vita ED, et al. Evaluation of mutant huntingtin and neurofilament proteins as potential markers in Huntington's disease. Sci TransI Med. 2018; 10: 7108. PubMed: https://www.ncbi.nlm.nih.gov/pubmed/30209243

120. Tippett LJ, Waldvogel HJ, Snell RG, Vonsattel JP, Young AB, et al. The complexity of clinical Huntington's disease: Developments in molecular genetics, neuropathology and neuroimaging biomarkers. Adv Neurobiol. 2017; 15: 129-161.

PubMed: https://www.ncbi.nlm.nih.gov/pubmed/28674980
121. Santa-Cruz LD, Tapia R. Role of energy metabolic deficits and oxidative stress in excitotoxic spinal motor neuron degeneration in vivo. ASN Neuro. 2014; 6: 00138.

PubMed: https://www.ncbi.nlm.nih.gov/pubmed/24524836

122. Massey T, McAllister B, Jones L. Methods for assessing DNA repair and repeat expansion in Huntington's disease. Methods in Molecular Biology. 2018; 1780: 483-495.

PubMed: https://www.ncbi.nlm.nih.gov/pubmed/29856032

123. Balakrishnan R, Manivasagam T, Justin Thenmozhi A, Essa $\mathrm{MM}$, Elangovan N. Spices and Huntington's disease. In Food for Huntington's Disease. 2018; 87-104.

124. Zheng J, Winderickx J, Franssens V, Liu B. A mitochondria-associated oxidative stress perspective on Huntington's disease. Front Mol Neurosci. 2018; 11: 329

PubMed: https://www.ncbi.nlm.nih.gov/pubmed/30283298

125. Wang J, Pfleger C, Friedman L, Vittorino R, Zhao W, et al. Potential application of grape derived polyphenols in Huntington's disease. Transl Neurosci. 2010; 1: 95-100.

PubMed: https://www.ncbi.nlm.nih.gov/pubmed/21331299

126. Tasset I, Pontes AJ, Hinojosa AJ, de la Torre R, Túnez I. Olive oil reduces oxidative damage in a 3-nitropropionic acid-induced Huntington's disease-like rat model. Nutr Neurosci. 2011; 14: 106-111. PubMed: https://www.ncbi.nlm.nih.gov/pubmed/21756531

127. Carito V, Ceccanti M, Tarani L, Ferraguti G, Chaldakov GN, et al. Neurotrophins' modulation by olive polyphenols. Curr Med Chem. 2016; 23: 3189-3197.

PubMed: https://www.ncbi.nlm.nih.gov/pubmed/27356540

128. Denny Joseph KM, Muralidhara. Combined oral supplementation of fish oil and quercetin enhances neuroprotection in a chronic rotenone rat model: Relevance to Parkinson's disease. Neurochem Res. 2015; 40: 894-905.

PubMed: https://www.ncbi.nlm.nih.gov/pubmed/25687767

129. Ehrnhoefer DE, Duennwald M, Markovic P, Wacker JL, Engemann S, et al. Green tea (-)-epigallocatechin-gallate modulates early events in Huntingtin misfolding and reduces toxicity in Huntington's disease models. Hum Mol Genet. 2006; 15: 2743-2751.

PubMed: https://www.ncbi.nlm.nih.gov/pubmed/16893904

130. Fu J, Jin J, Cichewicz RH, Hageman SA, Ellis TK, et al. Trans-(-)- $\varepsilon-$ viniferin increases mitochondrial sirtuin 3 (SIRT3), activates AMPactivated protein kinase (AMPK), and protects cells in models of Huntington disease. J Biol Chem. 2012; 287: 24460-24472. PubMed: https://www.ncbi.nlm.nih.gov/pubmed/22648412

131. Aarsland D, Creese B, Politis M, Chaudhuri KR, FfytcheDH, et al. Cognitive decline in Parkinson disease. Nat Rev Neurol. 2017; 13: 217-231. PubMed: https://www.ncbi.nlm.nih.gov/pubmed/28257128

132. Jain KK. Neuroprotection in Parkinson disease. In: The Handbook of Neuroprotection. Humana, New York, NY. 2019.

133. Elgayar SAM, Abdel-Hafez AAM, Gomaa AMS, Elsherif R. Vulnerability of glia and vessels of rat substantia nigra in rotenone Parkinson model. Ultrastruct Pathol. 2018; 42: 181-192. PubMed: https://www.ncbi.nlm.nih.gov/pubmed/29466086

134. Makletsova MG, Syatkin SP, Poleshchuk VV, Urazgildeeva GR, Chigaleychik LA, et al. Polyamines in Parkinson's disease: Their role in oxidative stress induction and protein aggregation. $J$ Neurol Res. 2019; 9: 1-7.

135. Mhyre TR, Boyd JT, Hamill RW, Maguire-Zeiss K. Parkinson's Disease. Subcellular Biochemistry. 2012; 65: 389-455.

PubMed: https://www.ncbi.nlm.nih.gov/pubmed/23225012 
136. Poewe W, Seppi K, Tanner CM. Parkinson disease. Nat Rev Dis Primers. 2017; 3: 17013

PubMed: https://www.ncbi.nlm.nih.gov/pubmed/28332488

137. Vivekanantham S, Shah S, Dewji R, Khatri C, Ologunde R, et al Neuroinflammation in Parkinson's disease: Role in neurodegeneration and tissue repair. Int J Neurosci. 2015; 125: 717-725.

PubMed: https://www.ncbi.nlm.nih.gov/pubmed/25364880

138. Gelders G, Baekelandt V, van der Perren A. Linking neuroinflammation and neurodegeneration in Parkinson's disease. J Immunol Res. 2018; 2018: 4784268.

PubMed: https://www.ncbi.nlm.nih.gov/pubmed/29850629

139. Hassanzadeh K, Rahimmi A. Oxidative stress and neuroinflammation in the story of Parkinson's disease: Could targeting these pathways write a good ending? J Cell Physiol. 2018; 234: 23-32.

PubMed: https://www.ncbi.nlm.nih.gov/pubmed/30078201

140. Dias V, Junn E, Mouradian MM. The role of oxidative stress in Parkinson's disease. J Parkinson's Dis. 2013; 3: 461-491. PubMed: https://www.ncbi.nlm.nih.gov/pubmed/24252804

141. ZhangS, WangR,WangG. Impactofdopamineoxidationondopaminergic neurodegeneration. ACS Chem Neurosci. 2019; 10: 945-953. PubMed: https://www.ncbi.nlm.nih.gov/pubmed/30592597

142. Nobili A, Latagliata EC, Viscomi MT. Dopamine neuronal loss contributes to memory and reward dysfunction in a model of Alzheimer's disease. Nat Commun. 2017; 8: 14727.

PubMed: https://www.ncbi.nlm.nih.gov/pubmed/28367951

143. Youssef SB, Brisson G, Doucet-Beaupre H, Castonguay A-M, Gora C, et al. Neuroprotective benefits of grape seed and skin extract in a mouse model of Parkinson's disease. Nutr Neurosci. 2019; 1-15. PubMed: https://www.ncbi.nlm.nih.gov/pubmed/31131731

144. Blesa J, Trigo-Damas I, Quiroga-Varela A, Jackson-Lewis VR. Oxidative stress and Parkinson's disease. Front Neuroanat. 2015; 9: 91. PubMed: https://www.ncbi.nlm.nih.gov/pubmed/26217195

145. Bose A, Beal MF. Mitochondrial dysfunction in Parkinson's disease. $J$ Neurochem. 2016; 139: 216-231.

PubMed: https://www.ncbi.nlm.nih.gov/pubmed/27546335

146. Pamphlett R. Uptake of environmental toxicants by the locus ceruleus: A potential trigger for neurodegenerative, demyelinating and psychiatric disorders. Med Hypotheses. 2014; 82: 97-104. PubMed: https://www.ncbi.nlm.nih.gov/pubmed/24315447

147. Rizor A, Pajarillo E, Johnson J, Aschner M, Lee E. Astrocytic oxidative/ nitrosative stress contributes to Parkinson's disease pathogenesis: The dual role of reactive astrocytes. Antioxidants. 2019; 8: 265. PubMed: https://www.ncbi.nlm.nih.gov/pubmed/31374936

148. Anh HM, Linh DM, Dung VM, Thao DTP. Evaluating dose- and timedependent effects of vitamin C treatment on a Parkinson's disease fly model. Parkinson's Dis. 2019; 2019: 9720546

PubMed: https://www.ncbi.nlm.nih.gov/pubmed/30719278

149. Hemmati-Dinarvand M, Saedi S, Valilo M, Kalantary-Charvadeh A Sani MA, et al. Oxidative stress and Parkinson's disease: Conflict of oxidant-antioxidant systems. Neurosci Lett. 2019; 709: 134296. PubMed: https://www.ncbi.nlm.nih.gov/pubmed/31153970

150. Monzani E, Nicolis S, Dell'Acqua S, Capucciati A, Bacchella C, et al. Dopamine, oxidative stress and protein-quinone modifications in Parkinson's and other neurodegenerative diseases. Angewandte Chemie International Edition. 2018; 58: 6512-6527.

PubMed: https://www.ncbi.nlm.nih.gov/pubmed/30536578

151. Yan MH, Wang X, Zhu X. Mitochondrial defects and oxidative stress in Alzheimer disease and Parkinson disease. Free Radic Biol Med. 2013. 62: 90-101.

PubMed: https://www.ncbi.nlm.nih.gov/pubmed/23200807
152. Bhat AH, Dar KB, Anees S, Zargar MA, Masood A, et al. Oxidative stress, mitochondrial dysfunction and neurodegenerative diseases: A mechanistic insight. Biomed Pharmacother. 2015; 74: 101-110. PubMed: https://www.ncbi.nlm.nih.gov/pubmed/26349970

153. Islam MT. Oxidative stress and mitochondrial dysfunction-linked neurodegenerative disorders. Neurol Res. 2016; 39: 73-82. PubMed: https://www.ncbi.nlm.nih.gov/pubmed/27809706

154. Kumar H, Lim HW, More SV, Kim BW, Koppula S, et al. The role of free radicals in the aging brain and Parkinson's disease: Convergence and parallelism. Int J Mol Sci. 2012; 13: 10478-10504.

PubMed: https://www.ncbi.nlm.nih.gov/pubmed/22949875

155. Ares-Santos SN, Granado N, Moratalla R. The role of dopamine receptors in the neurotoxicity of methamphetamine. J Intern Med. 2013; 273. PubMed: https://www.ncbi.nlm.nih.gov/pubmed/23600399

156. Wei Z, Li X, Li X, Liu Q, Cheng Y. Oxidative stress in Parkinson's disease: A systematic review and meta-analysis. FrontMol Neurosci. 2018;11:236. PubMed: https://www.ncbi.nlm.nih.gov/pubmed/30026688

157. Sechi G, Sechi E, Fois C, Kumar N. Advances in clinical determinants and neurological manifestations of $B$ vitamin deficiency in adults. Nutr Rev. 2016; 74: 281-300

PubMed: https://www.ncbi.nlm.nih.gov/pubmed/27034475

158. Ticinesi A, Meschi T, Lauretani F, Felis G, Franchi F, et al. Nutrition and inflammation in older individuals: Focus on vitamin $D, n-3$ polyunsaturated fatty acids and whey proteins. Nutrients. 2016; 8: 186. PubMed: https://www.ncbi.nlm.nih.gov/pubmed/27043616

159. Yeshokumar AK, Saylor D, Kornberg MD, Mowry EM. Evidence for the importance of vitamin D status in neurologic conditions. Curr Treat Options Neurol. 2015; 17: 51

PubMed: https://www.ncbi.nlm.nih.gov/pubmed/26538263

160. Mischley LC, Lau RC, Bennett RD. Role of diet and nutritional supplements in Parkinson's disease progression. Oxid Med Cell Longev. 2017; 2017: 6405278.

PubMed: https://www.ncbi.nlm.nih.gov/pubmed/29081890

161. Zhen C, Li D, Wang H, Wang P, Zhang W, et al. Tea consumption and risk of Parkinson's disease: A meta-analysis. Neurology Asia. 2019; 24: $31-40$.

162. Dietiker C, Kim S, Zhang Y, Christine CW. Characterization of vitamin B12 supplementation and correlation with clinical outcomes in a large longitudinal study of early Parkinson's disease. J Mov Disord. 2019; 12: 91-96.

PubMed: https://www.ncbi.nlm.nih.gov/pubmed/31158942

163. McCarter SJ, Teigen LM, McCarter AR, Benarroch EE, St Louis EK, et al. Low vitamin B12 and Parkinson disease: Potential link to reduced cholinergic transmission and severity of disease. Mayo Clin Proc. 2019; 94: 757-762

PubMed: https://www.ncbi.nlm.nih.gov/pubmed/31054604

164. Shen L. Associations between B vitamins and Parkinson's disease. Nutrients. 2015; 7: 7197-7208.

PubMed: https://www.ncbi.nlm.nih.gov/pubmed/26343714

165. Zhao X, Zhang M, Li C, Jiang X, Su Y, et al. Benefits of vitamins in the treatment of Parkinson's disease. Oxid Med Cell Longev. 2019; 2019: 9426867

PubMed: https://www.ncbi.nlm.nih.gov/pubmed/30915197

166. Heo $\mathrm{HJ}$, Lee $\mathrm{CY}$. Protective effects of quercetin and vitamin $\mathrm{C}$ against oxidative stress-induced neurodegeneration. J Agric Food Chem. 2004; 52: 7514-7517

PubMed: https://www.ncbi.nlm.nih.gov/pubmed/15675797

167. Popovic LM, Mitic NR, Miric D, Miric D, Bisevac B, et al. Influence of vitamin $C$ supplementation on oxidative stress and neutrophil 
inflammatory response in acute and regular exercise. Oxid Med Cell Longev. 2015; 2015: 295497.

PubMed: https://www.ncbi.nlm.nih.gov/pubmed/25802681

168. Hughes KC, Gao X, Kim IY, Rimm E, Wang M, et al. Intake of antioxidant vitamins and risk of Parkinson's disease. Mov Disord. 2016; 31: 19091914

PubMed: https://www.ncbi.nlm.nih.gov/pubmed/27787934

169. Luo $X$, Ou R, Dutta $R$, Tian $Y$, Xiong $H$, et al. Association between serum vitamin D levels and Parkinson's disease: A systematic review and meta-analysis. Front Neurol. 2018; 9: 909.

PubMed: https://www.ncbi.nlm.nih.gov/pubmed/30483205

170. Ross GW, Petrovitch $H$, Abbott RD. Serum vitamin D and risk of Parkinson's disease. Mov Disord. 2016; 31: 933-935. PubMed: https://www.ncbi.nlm.nih.gov/pubmed/27091700

171. Soliman RH, Oraby MI, Hussein M, El-Shafy SA, Mostafa S. Could vitamin $D$ deficiency have an impact on motor and cognitive function in Parkinson's disease? Egypt J Neurol Psychiatr Neurosurg. 2019; 55: 34

172. Wang L, Evatt ML, Maldonado LG, Perry WR, Ritchie JC, et al. Vitamin D from different sources is inversely associated with Parkinson disease. Mov Disord. 2015; 30: 560-566.

PubMed: https://www.ncbi.nlm.nih.gov/pubmed/25545356

173. Zhou Z, Zhou R, Zhang Z, Li K. The Association between vitamin D status, vitamin $D$ supplementation, sunlight exposure, and Parkinson's disease: A systematic review and meta-analysis. Med Sci Monit. 2019b; 25: 666-674.

PubMed: https://www.ncbi.nlm.nih.gov/pubmed/30672512

174. Lv Z, Qi H, Wang L, Fan X, Han F, et al. Vitamin D status and Parkinson's disease: A systematic review and meta-analysis. Neurol Sci. 2014; 35:1723-1730.

PubMed: https://www.ncbi.nlm.nih.gov/pubmed/24847960

175. Taghizadeh M, Tamtaji OR, Dadgostar E, Kakhaki RD, Bahmani F, et al. The effects of omega-3 fatty acids and vitamin E co-supplementation on clinical and metabolic status in patients with Parkinson's disease: A randomized, double-blind, placebo-controlled trial. Neurochem Int. 2017; 108: 183-189.

PubMed: https://www.ncbi.nlm.nih.gov/pubmed/28342967

176. Filograna R, Beltramini $M$, Bubacco L, Bisaglia M. Anti-oxidants in Parkinson's disease therapy: A critical point of view. Curr Neuropharmacol. 2016; 14: 260-271.

PubMed: https://www.ncbi.nlm.nih.gov/pubmed/26517052

177. Trotta E, Bortolotti S, Fugazzotto G, Gellera C, Montagnese S, et al. Familial vitamin E deficiency: Multiorgan complications support the adverse role of oxidative stress. Nutrition. 2019; 63-64: 57-60. PubMed: https://www.ncbi.nlm.nih.gov/pubmed/30933726

178. Fahn S. A pilot trial of high-dose alpha-tocopherol and ascorbate in early Parkinson's disease. Ann Neurol. 1992; 32: 128-132. PubMed: https://www.ncbi.nlm.nih.gov/pubmed/1510371

179. Bazan NG. Docosanoids and elovanoids from omega-3 fatty acids are pro-homeostatic modulators of inflammatory responses, cell damage and neuroprotection. Mol Aspects Med. 2018; 64:18-33. PubMed: https://www.ncbi.nlm.nih.gov/pubmed/30244005

180. De Lau LM, Bornebroek M, Witteman JC, Hofman A, Koudstaal PJ, et al. Dietary fatty acids and the risk of Parkinson disease: The Rotterdam study. Neurology. 2005; 64: 2040-2045.

PubMed: https://www.ncbi.nlm.nih.gov/pubmed/15985568

181. Munusamy U, Abdullah SNA. Vitamin E. Ozturk M., Hakeem K. Springer Cham. Plant and Human Health. 2019; 2.

182. Zanetti M, Grillo A, Losurdo P, Panizon E, Mearelli F, et al. Omega-3 polyunsaturated fatty acids: Structural and functional effects on the vascular wall. Biomed Res Int. 2015; 2015: 791978

PubMed: https://www.ncbi.nlm.nih.gov/pubmed/26301252

183. Darvesh AS, McClure M, Sadana P, Paxos C, Geldenhuys WJ, et al. Neuroprotective properties of dietary polyphenols in Parkinson's disease. Neuroprotective Effects of Phytochemicals in Neurological Disorders. 2017.

184. Kujawska M, Jodynis-Liebert J. Polyphenols in Parkinson's disease: A systematic review of in vivo studies. Nutrients. 2018; 10: 642. PubMed: https://www.ncbi.nlm.nih.gov/pubmed/29783725

185. Farzaei MH, Bahramsoltani R, Abbasabadi Z, Braidy N, Nabavi SM. Role of green tea catechins in prevention of age-related cognitive decline: Pharmacological targets and clinical perspective. J Cell Physiol. 2019; 234: 2447-2459.

PubMed: https://www.ncbi.nlm.nih.gov/pubmed/30187490

186. Jung UJ, Kim SR. Beneficial effects of flavonoids against Parkinson's disease. J Med Food. 2018; 21: 421-432.

PubMed: https://www.ncbi.nlm.nih.gov/pubmed/29412767

187. Xing L, Zhang H, Qi R, Tsao R, Mine Y. Recent advances in the understanding of the health benefits and molecular mechanisms associated with green tea polyphenols. J Agric Food Chem. 2019; 67: 1029-1043

PubMed: https://www.ncbi.nlm.nih.gov/pubmed/30653316

188. Gao X, Cassidy A, Schwarzschild MA, Rimm EB, Ascherio A. Habitual intake of dietary flavonoids and risk of Parkinson disease. Neurology. 2012; 78: 1138-1145.

PubMed: https://www.ncbi.nlm.nih.gov/pubmed/22491871

189. Garg SK, Shukla A, Choudhury S. Polyphenols and flavonoids. Nutraceuticals in Veterinary Medicine. 2019.

190. Sánchez B, Delgado S, Blanco-Miguez A, Lourenço A, Gueimonde M, et al. Probiotics, gut microbiota, and their influence on host health and disease. Mol Nutr Food Res. 2017; 61: 1600-2240. PubMed: https://www.ncbi.nlm.nih.gov/pubmed/27500859

191. Tamtaji OR, Taghizadeh M, Kakhaki RD, Kouchaki E, Bahmani F, et al. Clinical and metabolic response to probiotic administration in people with Parkinson's disease: A randomized, double-blind, placebocontrolled trial. Clin Nutr. 2018; 38.

PubMed: https://www.ncbi.nlm.nih.gov/pubmed/29891223

192. De Aguilar JG. Lipid biomarkers for amyotrophic lateral sclerosis. Front Neurol. 2019; 10: 284.

PubMed: https://www.ncbi.nlm.nih.gov/pubmed/31019485

193. Luisetto M, Almukhtar N, Rafa AY, Ahmadabadi BN, Mashori GR, et al Role of plants, environmental toxins and physical neurotoxicological factors in amyotrophic lateral sclerosis, Alzheimer disease and other neurodegenerative diseases. J Neurosci Neurol Disord. 2019; 3: 001-086.

194. Nowicka N, Juranek J, Juranek JK, Wojtkiewicz J. Risk factors and emerging therapies in amyotrophic lateral sclerosis. Int J Mol Sci. 2019; 20: 2616

PubMed: https://www.ncbi.nlm.nih.gov/pubmed/31141951

195. Niedermeyer S, Murn M, Choi PJ. Respiratory failure in amyotrophic lateral sclerosis. Recent Advances in Chest Medicine. 2019; 155: 401-408.

196. Okamoto K. Risk factors in amyotrophic lateral sclerosis. Current Topics in Environmental Health and Preventive Medicine. 2018.

197. Grossman M. Amyotrophic lateral sclerosis - A multisystem neurodegenerative disorder. Nat Rev Neurol. 2019; 15: 5-6. PubMed: https://www.ncbi.nlm.nih.gov/pubmed/30446736

198. Valko K, Ciesla L. Amyotrophic lateral sclerosis. Prog Med Chem. 2019; 58: 63-117.

PubMed: https://www.ncbi.nlm.nih.gov/pubmed/30879475 
199. Butti Z, Patten SA. RNA Dysregulation in Amyotrophic Lateral Sclerosis. Front Genet. 2019; 9: 712

PubMed: https://www.ncbi.nlm.nih.gov/pubmed/30723494

200. Trias E, Ibarburu S, Barreto-Nunez R, Babdor J, Maciel TT, et al Post-paralysis tyrosine kinase inhibition with masitinib abrogates neuroinflammation and slows disease progression in inherited amyotrophic lateral sclerosis. J Neuroinflammation. 2016; 13: 177. PubMed: https://www.ncbi.nlm.nih.gov/pubmed/27400786

201. Beers DR, Appel SH. Immune dysregulation in amyotrophic lateral sclerosis: Mechanisms and emerging therapies. The LANCET Neurology. 2019; 18: 211-220.

PubMed: https://www.ncbi.nlm.nih.gov/pubmed/30663610

202. Pansarasa O, Bordoni M, Diamanti L, et al., SOD1 in amyotrophic lateral sclerosis: Ambivalent behavior connected to the disease. Int J Mol Sci. 2018; 19: 1345.

PubMed: https://www.ncbi.nlm.nih.gov/pubmed/29751510

203. Blasco H, Garcon G, Patin F, Veyrat-Durebex C, Boyer J, et al. Panel of oxidative stress and inflammatory biomarkers in ALS: A pilot study. Can J Neurol Sci. 2017; 44: 90-95.

PubMed: https://www.ncbi.nlm.nih.gov/pubmed/27774920

204. Castanedo-Vazquez D, Bosque-Varela P, Sainz-Pelayo A, Riancho J. Infectious agents and amyotrophic lateral sclerosis: Another piece of the puzzle of motor neuron degeneration. J Neurol. 2019; 266: 27-36. PubMed: https://www.ncbi.nlm.nih.gov/pubmed/29845377

205. Zeldich E, Chen CD, Boden E, Howat B, Nasse JS, et al. Klotho is neuroprotective in the superoxide dismutase $\left(\mathrm{SOD}^{\mathrm{G}}{ }^{\mathrm{G3A}}\right)$ mouse model of ALS. J Mol Neurosci. 2019; 69: 264-285.

PubMed: https://www.ncbi.nlm.nih.gov/pubmed/31250273

206. Granatiero V, Manfredi G. Mitochondrial transport and turnover in the pathogenesis of amyotrophic lateral sclerosis. Biology, 2019; 8: 36. PubMed: https://www.ncbi.nlm.nih.gov/pubmed/31083575

207. Sasaki S, Iwata M. Mitochondrial alterations in the spinal cord of patients with sporadic amyotrophic lateral sclerosis. J Neuropathol Exp Neurol. 2007; 66: 10-16.

PubMed: https://www.ncbi.nlm.nih.gov/pubmed/17204932

208. Ohta Y, Nomura E, Shang J, Feng T, Huang Y, et al. Enhanced oxidative stress and the treatment by edaravone in mice model of amyotrophic lateral sclerosis. J Neurosci Res. 2018; 97.

PubMed: https://www.ncbi.nlm.nih.gov/pubmed/30565312

209. Wang Z, Bai Z, Qin X, Cheng Y. Aberrations in oxidative stress markers in amyotrophic lateral sclerosis: A systematic review and metaanalysis. Oxid Med Cell Longev. 2019; 2019: 1712323.

PubMed: https://www.ncbi.nlm.nih.gov/pubmed/31281567

210. Ragagnin AMG, Shadfar S, Vidal M, Jamali MS, Atkin JD. Motor neuron susceptibility in ALS/FTD. Front Neurosci. 2019; 13: 532. PubMed: https://www.ncbi.nlm.nih.gov/pubmed/31316328

211. Smith EF, Shaw PJ, de Vos KJ. The role of mitochondria in amyotrophic lateral sclerosis. Neurosci Lett. 2019; 710: 132933.

PubMed: https://www.ncbi.nlm.nih.gov/pubmed/28669745

212. Said Ahmed M, Hung WY, Zu JS, Hockberger PE, Siddique T. Increased reactive oxygen species in familial amyotrophic lateral sclerosis with mutations in SOD1. J Neurol Sci. 2000; 176: 88-94.

PubMed: https://www.ncbi.nlm.nih.gov/pubmed/10930589

213. Moretti M, Budni J, Ribeiro CM, Rieger DK, Leal RB, et al. Subchronic administration of ascorbic acid elicits antidepressant-like effect and modulates cell survival signaling pathways in mice. J Nutr Biochem. 2016; 38: 50-56.

PubMed: https://www.ncbi.nlm.nih.gov/pubmed/27721116

214. Blasco H, Corcia P, Moreau C, Veau S, Fournier C, et al. 1H-NMR-based metabolomic profiling of CSF in early amyotrophic lateral sclerosis. PLoS ONE. 2010; 5: 13223.

PubMed: https://www.ncbi.nlm.nih.gov/pubmed/20949041

215. Nagano S, Fujii $Y$, Yamamoto T, Taniyama M, Fukada $K$, et al. The efficacy of trientine or ascorbate alone compared to that of the combined treatment with these two agents in familial amyotrophic lateral sclerosis model mice. Exp Neurol. 2003; 179: 176-180. PubMed: https://www.ncbi.nlm.nih.gov/pubmed/12618124

216. Camu W, Tremblier B, Plassot C, Alphandery S, Salsac C, et al. 2014 Vitamin D confers protection to motoneurons and is a prognostic factor of amyotrophic lateral sclerosis. Neurobiol Aging. 2014;35: 1198-1205. PubMed: https://www.ncbi.nlm.nih.gov/pubmed/24378089

217. Gianforcaro A, Hamadeh MJ. Vitamin D as a potential therapy in amyotrophic lateral sclerosis. CNS Neurosci Ther. 2014; 20:101-111. PubMed: https://www.ncbi.nlm.nih.gov/pubmed/24428861

218. Veldink JH, Kalmijn S, Groeneveld GJ, Wunderink W, Koster A, et al. Intake of polyunsaturated fatty acids and vitamin $E$ reduces the risk of developing amyotrophic lateral sclerosis. J Neurol Neurosurg Psychiatry. 2007; 78: 779-779.

PubMed: https://www.ncbi.nlm.nih.gov/pubmed/16648143

219. Wang H, O'Reilly EJ, Weisskopf MG, Logroscino G, McCullough ML, et al. Vitamin $E$ intake and risk of amyotrophic lateral sclerosis: A pooled analysis of data from 5 prospective cohort studies. Am J Epidemiol. 2011; 173: 595-602.

PubMed: https://www.ncbi.nlm.nih.gov/pubmed/21335424

220. Caragounis A, Price K, Soon CPW, Filiz G, Masters CL, et al. Zinc induces depletion and aggregation of endogenous TDP-43. Free Radical Biol Med. 2010; 48: 1152-1161.

PubMed: https://www.ncbi.nlm.nih.gov/pubmed/20138212

221. Urbi B, Owusu MA, Hughes I, Katz M, Broadley S, et al. Effects of cannabinoids in amyotrophic lateral sclerosis (ALS) murine models: A systematic review and meta-analysis. J Neurochem. 2018; 149. PubMed: https://www.ncbi.nlm.nih.gov/pubmed/30520038

222. Veyrat-Durebex C, Bris C, Codron P, Bocca C, Chupin S, et al. Metabolipidomics of fibroblasts and mitochondrial-endoplasmic reticulum extracts from ALS patients shows alterations in purine, pyrimidine, energetic, and phospholipid metabolisms. Mol Neurobiol. 2019; 56: 5780-5791.

PubMed: https://www.ncbi.nlm.nih.gov/pubmed/30680691

223. Gonçalves J, Rosado T, Soares S, Simão AY, Caramelo D, et al Cannabis and its secondary metabolites: Their use as therapeutic drugs, toxicological aspects, and analytical determination. Medicines (Basel). 2019; 6: 31.

PubMed: https://www.ncbi.nlm.nih.gov/pubmed/30813390 